\title{
LAG-3 regulates CD8+ $T$ cell accumulation and effector function in murine self- and tumor-tolerance systems
}

\author{
Joseph F. Grosso, ${ }^{1}$ Cristin C. Kelleher, ${ }^{1}$ Timothy J. Harris, ${ }^{1}$ Charles H. Maris, ${ }^{1}$ \\ Edward L. Hipkiss, ${ }^{1}$ Angelo De Marzo, ${ }^{2}$ Robert Anders, ${ }^{2}$ George Netto, ${ }^{2}$ Derese Getnet, ${ }^{1}$ \\ Tullia C. Bruno, ${ }^{1}$ Monica V. Goldberg, ${ }^{1}$ Drew M. Pardoll, ${ }^{1}$ and Charles G. Drake ${ }^{1}$
}

${ }^{1}$ Sidney Kimmel Comprehensive Cancer Center and 2Department of Pathology, Johns Hopkins University School of Medicine, Baltimore, Maryland, USA.

\begin{abstract}
Lymphocyte activation gene-3 (LAG-3) is a cell-surface molecule with diverse biologic effects on T cell function. We recently showed that LAG-3 signaling is important in $\mathrm{CD}^{+}$regulatory $\mathrm{T}$ cell suppression of autoimmune responses. Here, we demonstrate that LAG-3 maintains tolerance to self and tumor antigens via direct effects on $\mathrm{CD8}^{+} \mathrm{T}$ cells using 2 murine systems. Naive $\mathrm{CD8}^{+} \mathrm{T}$ cells express low levels of $\mathrm{LAG}-3$, and expression increases upon antigen stimulation. Our data show increased levels of LAG-3 protein on antigen-specific CD8 ${ }^{+}$ T cells within antigen-expressing organs or tumors. In vivo antibody blockade of LAG-3 or genetic ablation of the Lag-3 gene resulted in increased accumulation and effector function of antigen-specific $\mathrm{CDB}^{+} \mathrm{T}$ cells within organs and tumors that express their cognate antigen. Most notably, combining LAG-3 blockade with specific antitumor vaccination resulted in a significant increase in activated $\mathrm{CD8}^{+} \mathrm{T}$ cells in the tumor and disruption of the tumor parenchyma. A major component of this effect was CD4 independent and required LAG-3 expression by $\mathrm{CD8}^{+} \mathrm{T}$ cells. Taken together, these data demonstrate a direct role for LAG-3 on $\mathrm{CD8}^{+} \mathrm{T}$ cells and suggest that LAG-3 blockade may be a potential cancer treatment.
\end{abstract}

\section{Introduction}

$\mathrm{T}$ cell effector function and tolerance are controlled through multiple signaling pathways regulated by interactions with antigen-presenting cells. $T$ cell proliferation and effector function are positively regulated by various members of the $\mathrm{B} 7$ family interacting with costimulatory receptors as well as certain TNF family members and cytokines (1-4).

Negative regulation of $\mathrm{CD} 4^{+}$and $\mathrm{CD}^{+}$cell activation is controlled in part by cytotoxic lymphocyte antigen-4:B7 (CTLA-4:B7) (5) and PD-1:PD-L1 interactions (6, 7). Both CTLA-4 and PD-1 knockout mice develop systemic autoimmunity, although the phenotypes are qualitatively and quantitatively quite different (8-10). CTLA-4 plays an important role in the negative regulation of $\mathrm{CD} 4$ responses, but its direct role in $\mathrm{CD}^{+} \mathrm{T}$ cell regulation is less clear. CTLA-4 plays little apparent role in regulating responses of naive $\mathrm{T}$ cells (11); however, Gajewski and colleagues have reported evidence that CTLA-4 negatively regulates responses in primed $\mathrm{CD}^{+} \mathrm{T}$ cells (12). PD- 1 appears to play an important role in both early decisions related to peripheral $\mathrm{CD}^{+} \mathrm{T}$ cell tolerance $(13,14)$ and downregulating responses of primed and chronically antigen-stimulated $\mathrm{CD}^{+} \mathrm{T}$ cells $(15,16)$. In vitro data suggest that a combined program of costimulatory signals (i.e., lack of CD28 plus PD-1 signaling) results in both the generation and maintenance of $\mathrm{CD} 88^{+} \mathrm{T}$ cell tolerance (17).

Among the many molecules shown to qualitatively and quantitatively regulate $\mathrm{T}$ cell function, lymphocyte activation gene-3 (LAG-3) has garnered significant recent interest. LAG-3 is a CD4

Nonstandard abbreviations used: CTLA-4, cytotoxic lymphocyte antigen-4; LAG-3, lymphocyte activation gene-3; PD-1, programmed death-1; PD-L1, programmed death ligand-1; PIN, prostatic intraepithelial neoplasia; VV, Vaccinia virus.

Conflict of interest: C.G. Drake and D.M. Pardoll are inventors on a patent relevant to the subject of this manuscript and are thus potentially eligible to receive future royalties from licensing.

Citation for this article: J. Clin. Invest. 117:3383-3392 (2007). doi:10.1172/JCI31184 homolog originally cloned in 1990 (18). The gene for LAG-3 lies adjacent to the gene for CD4 on human chromosome 12 (12p13) and is approximately $20 \%$ identical to the CD 4 gene. LAG-3 is expressed on B cells, NK cells, tumor-infiltrating lymphocytes, and a subset of T cells (19). Recently, we showed that LAG-3 was relatively overexpressed on transgenic $\mathrm{T}$ cells rendered anergic in vivo by encounter with cognate self antigen (20). In this system, tolerized $\mathrm{T}$ cells displayed regulatory function both in vitro and in vivo, and in vitro regulatory activity was blocked with a LAG-3specific monoclonal antibody. By transducing naive $\mathrm{CD} 4^{+} \mathrm{T}$ cells with a full-length LAG-3 construct, we could confer in vitro regulatory activity. Interestingly, LAG-3 signaling may play a role in LAG-3mediated regulatory function. Transfection of a LAG-3 construct lacking the unique KIEELE signaling motif was not sufficient to mediate regulatory activity. Recent studies in humans have demonstrated selectively increased LAG-3 expression on tumor-infiltrating FoxP3 ${ }^{+}$regulatory $\mathrm{T}$ cells $(21)$.

Naive $\mathrm{CD} 8^{+} \mathrm{T}$ cells express low levels of LAG-3; however, expression dramatically increases in response to antigen stimulation (22). Observations using LAG-3-- mice demonstrate that $\mathrm{CD}^{+} \mathrm{T}$ cells undergo enhanced homeostatic proliferation in vivo if LAG-3 is absent (23). Similarly, in response to Sendai virus infection, $\mathrm{CD}^{+} \mathrm{T}$ cells expand several-fold more in LAG-3--- mice than in wild-type mice (24). Studies using human PBMCs also suggest a negative regulatory role for LAG-3, as LAG-3 antibody blockade combined with superantigen stimulation results in increased proliferation of $\mathrm{CD}^{+}$and $\mathrm{CD}^{+} \mathrm{T}$ cells compared with superantigen alone (25). A direct role for LAG-3 on CD8 $8^{+}$function has not yet been evaluated, nor has the role of LAG- 3 on antigen-specific $\mathrm{CD}^{+}$ $\mathrm{T}$ cell responses to tumor and self antigens been described.

Here, we utilized mouse strains that express influenza HA as a self antigen (C3-HA $\left.{ }^{\text {hi }}\right)$ or as a tumor/tissue antigen (ProHA $\times$ TRAMP) and wild-type or LAG-3-/- HA-specific CD8 ${ }^{+}$(clone 4) 
A
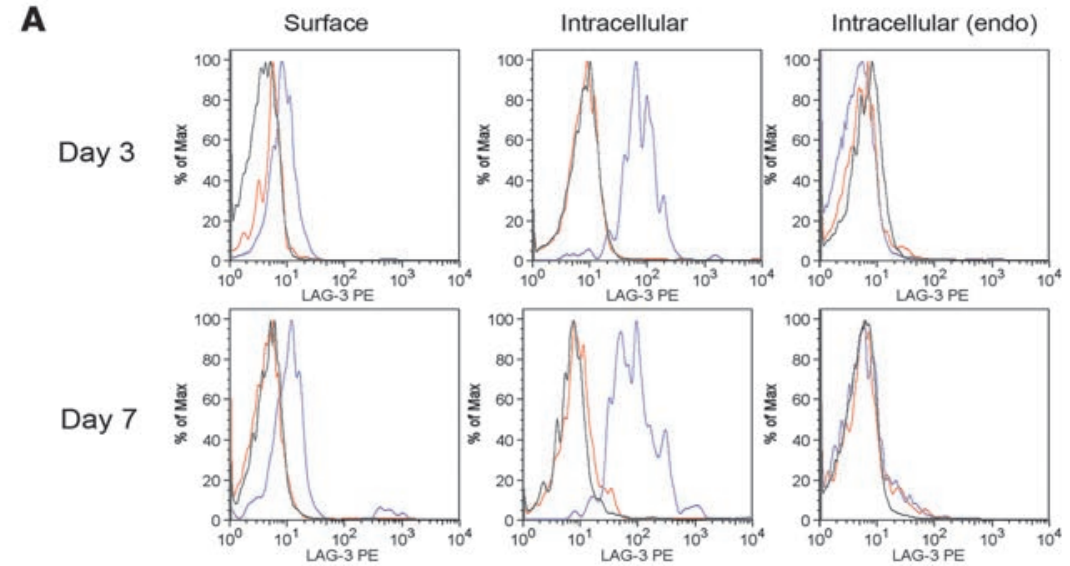

B
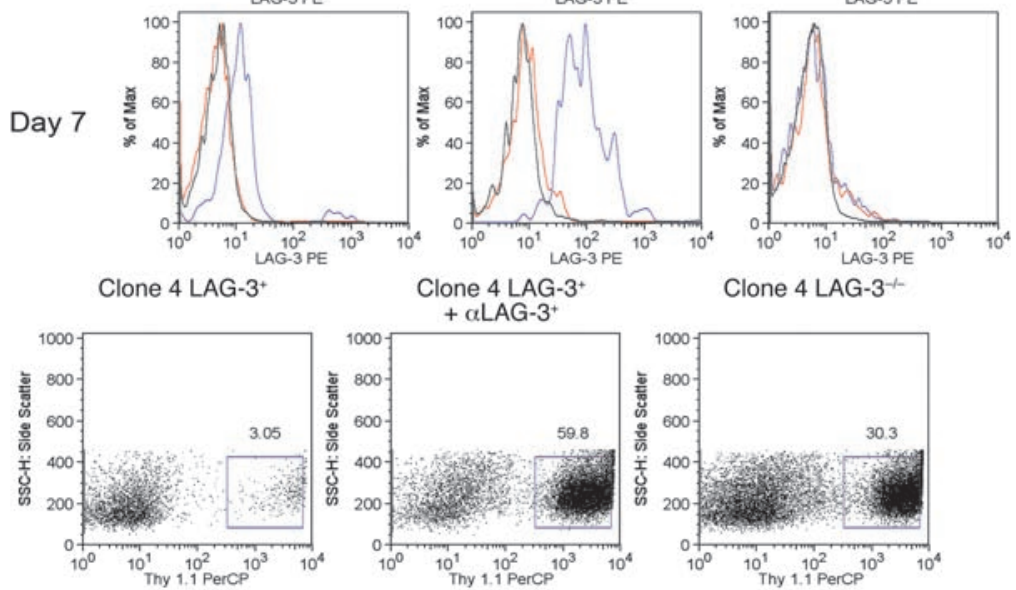

Clone 4 LAG- $3^{-1-}$

C
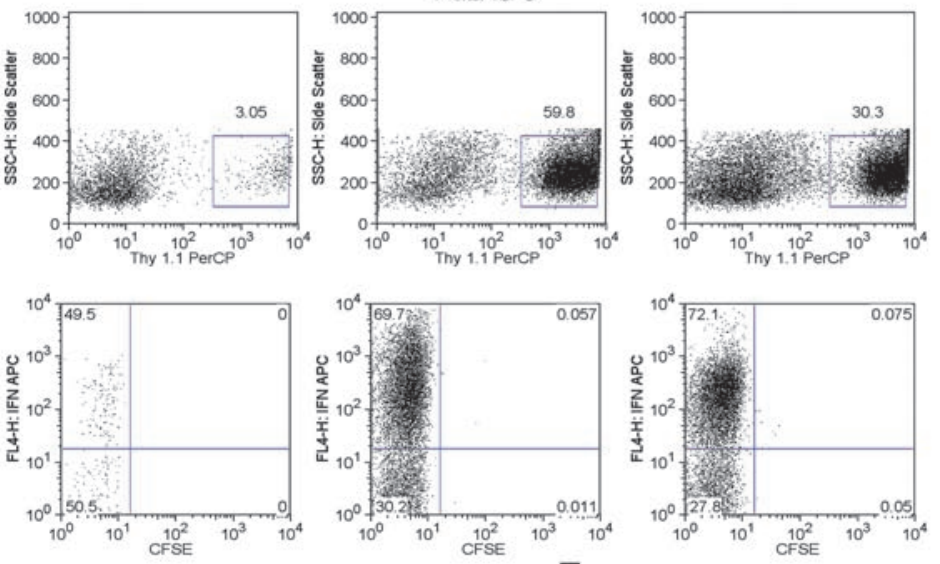

D
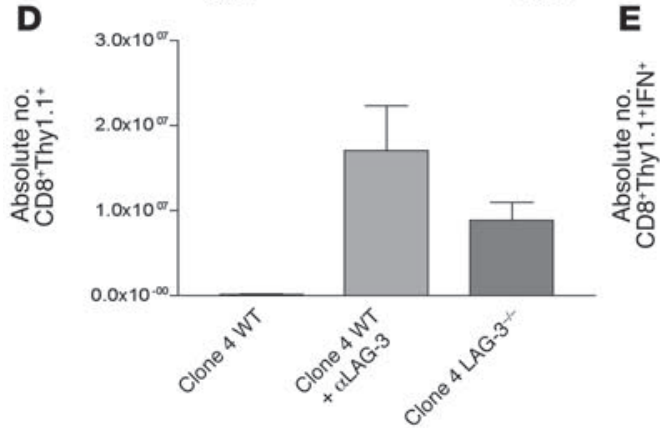

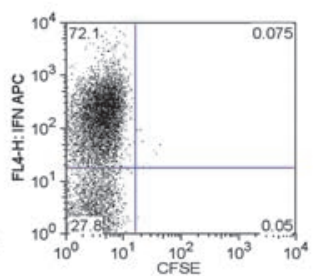

E

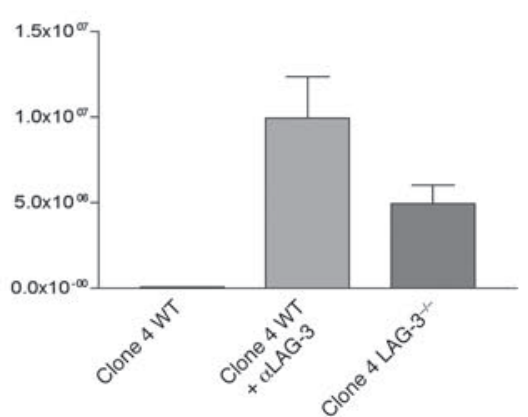

\section{Figure 1}

LAG-3 blockade enhances the accumulation of $\mathrm{HA}$-specific $\mathrm{CD} 8^{+}$cells in a model of self tolerance. We transferred $10^{6} \mathrm{LAG}^{-3^{+/+}}$or LAG-3-/-CD8 ${ }^{+}$Thy $1.1^{+}$ clone $4 \mathrm{CD}^{+}$cells into Thy $1.2^{+} \mathrm{C} 3-$ $\mathrm{HA}^{\text {high }}$ mice. Mice receiving antibody were given $0.2 \mathrm{mg} \alpha \mathrm{LAG}-3$ i.p. at the time of transfer and 3 days later. At indicated time points after transfer, singlecell suspensions were made from lungs and analyzed for LAG-3 expression and function. (A) $\mathrm{CD}^{+}$and Thy $1.1^{+}$were gated to determine expression of LAG-3 on $\mathrm{CD} 8^{+} \mathrm{T}$ cells taken directly from lungs of C3-HA mice. Both surface expression (left) and intracellular staining (middle and right) were performed for LAG-3 expression. Endogenous (endo) CD8 populations within lungs were also assessed. Blue lines, LAG-3; red lines, rat IgG1 isotype; black lines, LAG-3 ${ }^{-/-}$ cells. Max, maximum. (B) Lungs from C3-HA mice were analyzed 7 days after transfer for percentage of CD8 $8^{+}$Thy $1.1^{+}$ cells by staining for Thy 1.1 (C). Clonotypic cells from $\mathbf{B}$ were analyzed for division by dilution of CFSE and IFN- $\gamma$ production by intracellular staining after stimulation in vitro in the presence of HA peptide plus monensin for 5 hours. SSC-H, side scatter. (D and E) Absolute numbers of clonotypic and IFN- $\gamma^{+}$clonotypic cells/lung after $\alpha$ LAG-3 treatment or transfer of $\mathrm{LAG}-3^{-/-}$clone 4 cells. The mean from 3 mice per group is shown. Each experiment was performed 3 times with data from 1 representative experiment shown. cells to determine whether LAG-3 plays a role in $\mathrm{CD}^{+} \mathrm{T}$ cell tolerance. Our studies demonstrate an important role for LAG-3 in the regulation of $\mathrm{T}$ cell tolerance to both self and tumor antigens and demonstrate what we believe is a novel cell-intrinsic role for LAG-3 directly expressed by antigen-specific $\mathrm{CD}^{+} \mathrm{T}$ cells at the site of antigen expression. Overall, this study further defines LAG-3 as a promising target for enhancing cancer immunotherapy.

\section{Results}

LAG-3 blockade enhances T cell proliferation and effector function in a selftolerance model. C3-HA mice express influenza HA as a self antigen predominantly on epithelial cells within multiple tissues, and expression is highest in the pulmonary epithelia (26). Transfer of TCR transgenic HA-specific CD4+ cells into C3-HA mice results in the generation of tolerance, with the $\mathrm{CD} 4^{+}$cells unable to proliferate or produce IFN- $\gamma$ or IL-2 after an ex vivo stimulation with HA peptide (27). The C3-HA self-tolerance model also allowed us to identify LAG-3 as a protein present at high levels on Tregs (20). Expression and function of LAG-3 on $\mathrm{CD}^{+} \mathrm{T}$ cells has not, to our knowledge, been previously studied using in vivo models of tolerance. Using the C3-HA self-tolerance model, we therefore analyzed the ability of HA-specific CD8 ${ }^{+} \mathrm{T}$ cells (clone 4 ) to expand and produce cytokines in the presence and absence of LAG-3.

We first addressed the relative expression levels of LAG-3 on clone $4 \mathrm{CD}^{+}$cells after transfer into C3-HA mice. While naive $\mathrm{CD}^{+} \mathrm{T}$ cells do not express LAG-3, in vitro stimulation of clone 4 $\mathrm{CD}^{+}$cells with APCs plus HA peptide resulted in positive LAG-3 staining after 1 day in culture, with expression increasing over time (Supplemental Figure 1; supplemental material available online with this article; doi:10.1172/JCI31184DS1). Using real-time PCR, we quantitated the levels of LAG-3 mRNA from clone $4 \mathrm{CD} 8^{+} \mathrm{T}$ cells transferred into C3-HA mice. As demonstrated previously (20), 
A Surface (clonotypic)

Day 7

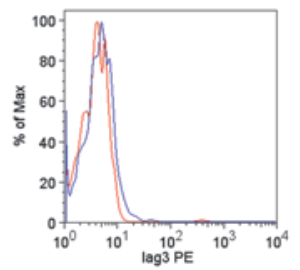

B Clone 4 LAG- $3^{+}$cells No VV-HA

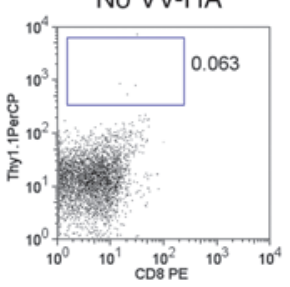

C

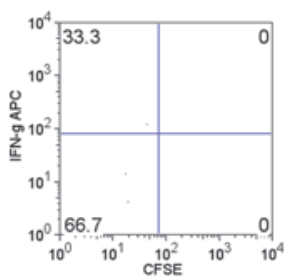

D

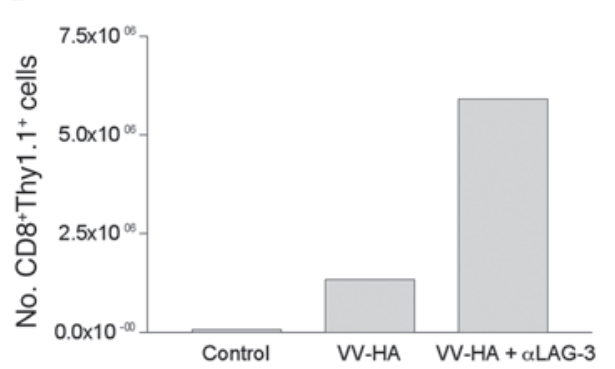

E
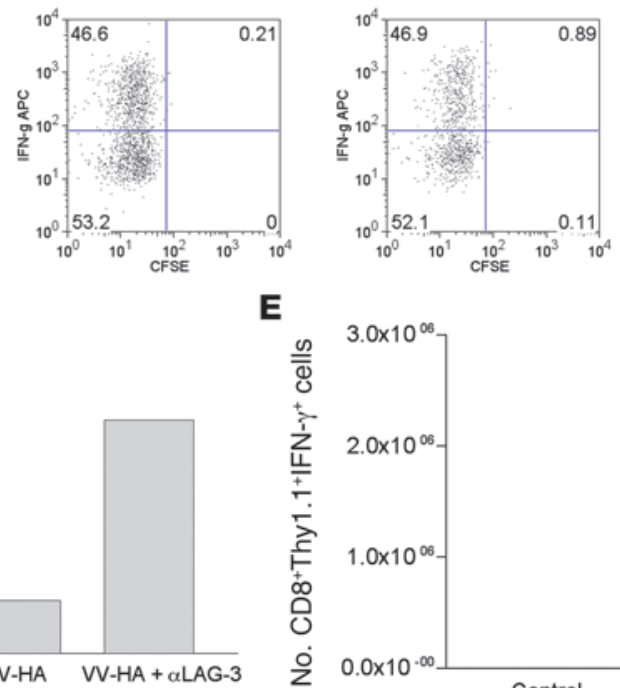

$\mathbf{F}$
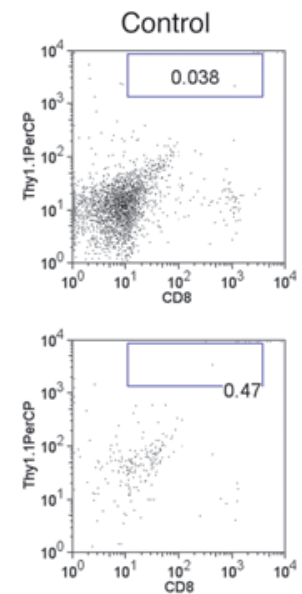

Intracellular (clonotypic)
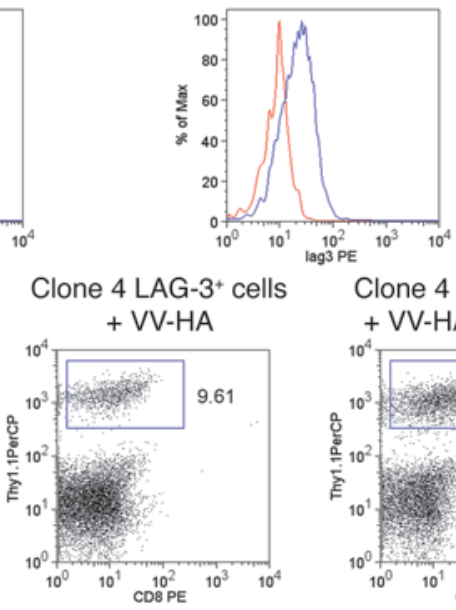

Clone 4 LAG-3+ cells

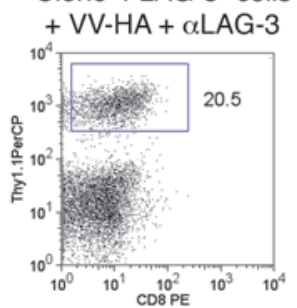

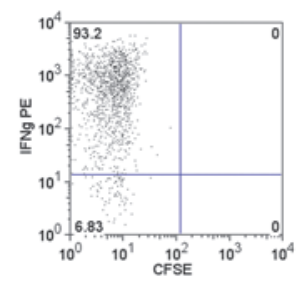

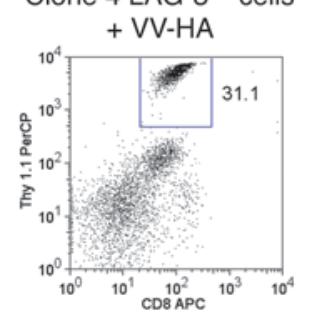

Intracellular (endogenous)

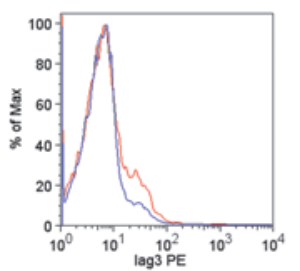

Clone 4 LAG-3 ${ }^{-1-}$ cells

- Blue line, LAG-3; line, rat lgG1 isotype; black line, LAG-3--/- cells. (B) $\alpha$ LAG-3 enhances the accumulation of clonotypic cells in prostates. We transferred $10^{6}$ LAG-3+/+ or LAG-3---CD8+Thy1.1+ clone $4 \mathrm{CD}^{+}$cells into ProHA $\times$ TRAMP mice. Mice were given VV-HA, VV-HA plus $\alpha$ LAG-3, or nothing at the time of transfer. Mice receiving $\alpha$ LAG-3 were given another dose 3 days later. Seven days after transfer, prostates and livers were collected and homogenized, and single-cell suspensions were analyzed for IFN- $\gamma$ by intracellular staining after stimulation in vitro in the presence of HA peptide plus monensin for 5 hours. Prostates were analyzed for (B) percentage of CD8+Thy1.1+ and (C) percentage of IFN- $\gamma^{+}$clonotypic cells. Absolute numbers of pooled prostates to determine (D) prostate-derived clonotypic cells and (E) IFN- $\gamma^{+}$clonotypic cells are shown. Error bars are absent because pooling was necessary to count $\mathrm{CD} 8^{+}$cells from prostate tissue. The results are representative of at least 4 experiments. (F) Enhanced accumulation of clone $4 \mathrm{CDB}^{+}$ cells using $\alpha$ LAG-3 is specific for organs expressing cognate antigen. Livers from ProHA $x$ TRAMP mice do not express the HA antigen (data not shown) and fail to attract and promote division of $\mathrm{HA}$-specific CD8 ${ }^{+} T$ cells. Data from 1 of at least 3 individual experiments are shown. PerCP, peridinin chlorophyll protein. 
A

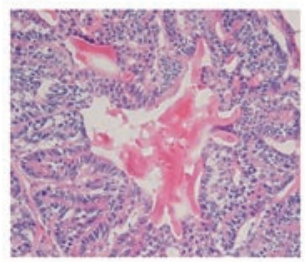

No Treatment

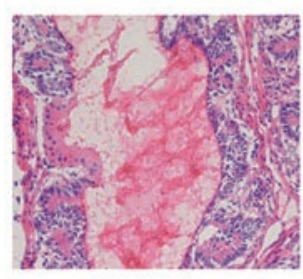

VV-HA

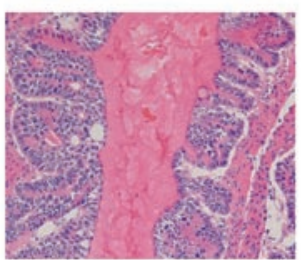

$\alpha$ LAG-3

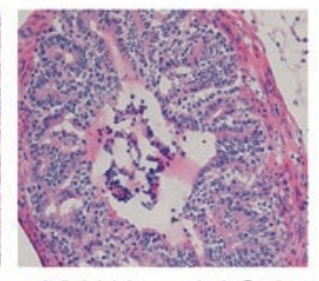

$\mathrm{V}-\mathrm{HA}+\alpha \mathrm{LAG}-3$

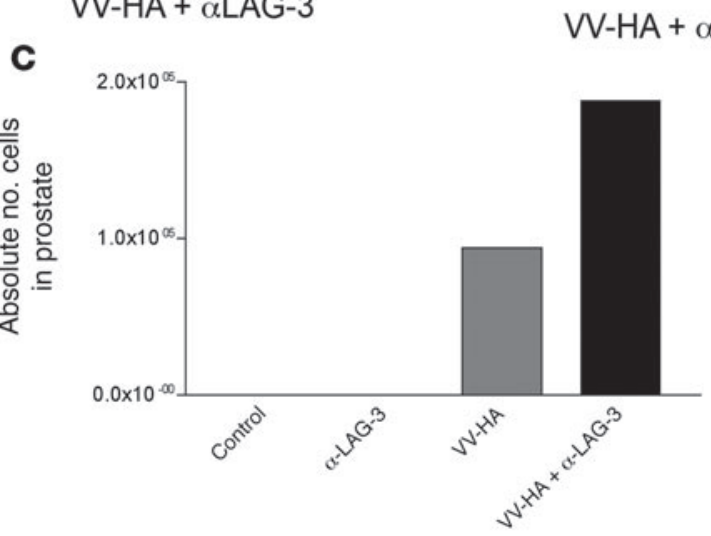

B

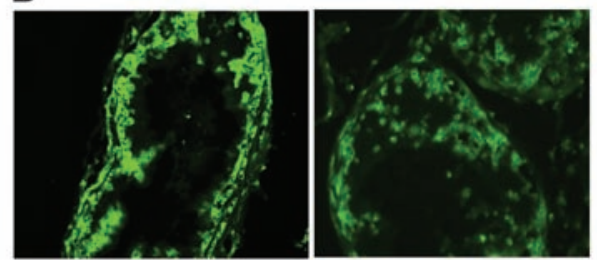

VV-HA

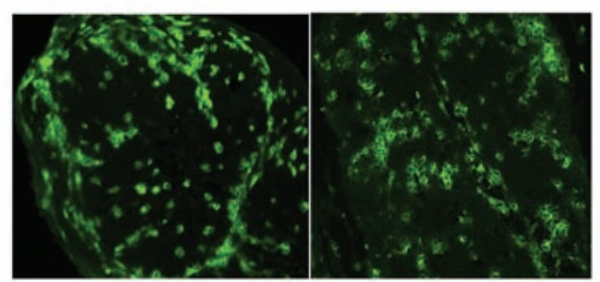

$\mathrm{V}-\mathrm{HA}+\alpha \mathrm{LAG}-3$
Figure 3

Visualization of clone 4 cells within prostates and tumor growth inhibition after $\alpha$ LAG-3 treatment. We transferred $10^{6}$ Thy $1.1^{+}$clone 4 $\mathrm{CD}^{+}$cells into $12-$ to 15 -weekold Thy $1.2^{+}$ProHA $\times$TRAMP mice. Mice received VV-HA with or without $\alpha$ LAG-3 on the same day as the cell transfers. Mice receiving $\alpha$ LAG-3 were reinjected with $\alpha$ LAG-3 3 days after transfer. Seven days after cell transfers, mice were sacrificed. Prostates from each group (control, $\alpha$ LAG-3, VV-HA, and VV-HA/ $\alpha$ LAG-3) were pooled and subsequently split into 2 groups: one for frozen sections (A and $\mathbf{B})$ and the other for flow cytometry analysis (C). Few prostate-infiltrating lymphocytes were seen in nontreated or $\alpha$ LAG-3treated mice. H\&E and Thy 1.1 immunofluorescence revealed lymphocytic infiltration after VV-HA and VV-HA/ $\alpha$ LAG-3 treatment with disrupted architecture and Thy1.1 cells invading the prostatic lumen only after VV-HA/ $\alpha$ LAG-3 treatment. For Thy 1.1 staining, no visible cells were present in control or $\alpha$ LAG-3 samples (data not shown). Original magnification, $\times 200$.
$\mathrm{HA}$-specific $\mathrm{CD}_{4}{ }^{+}$cells transferred into C3-HA mice have increased LAG-3 expression compared with HA-specific $\mathrm{CD}^{+}$cells transferred into immunized nontransgenic mice (Supplemental Figure 2). Clone $4 \mathrm{CD}^{+}$cells transferred into C3-HA mice had a similar amount of LAG-3 mRNA as 6.5 cells transferred into C3-HA; however, clone 4 cells from immunized nontransgenic mice had higher levels of LAG-3 message than $\mathrm{CD}^{+}$cells transferred into immunized nontransgenic mice (Supplemental Figure 2), suggesting LAG-3 may be expressed at higher levels on activated CD8 ${ }^{+}$ cells than on activated $\mathrm{CD} 4^{+}$cells. In vivo expression of LAG-3 protein was assessed at multiple time points after adoptive transfer of $10^{6}$ naive clone $4 \mathrm{CD} 8^{+}$cells or clone $4 \mathrm{CD} 8^{+} \mathrm{LAG}-3^{-/-}$cells into C3-HA mice using flow cytometry. Clone 4 CD $8^{+}$LAG-3 $3^{-/}$cells isolated from the lungs or lymph nodes did not express LAG-3 as expected (data not shown). However, wild-type clone $4 \mathrm{CD}^{+}$ cells directly isolated from the lungs (Figure 1A) and lung draining lymph nodes (data not shown) were positive for LAG-3 shortly after $T$ cell transfer.

We next determined whether HA-specific $\mathrm{CD}^{+}$cells expand or produce IFN- $\gamma$ after transfer into the C3-HA mouse and whether these processes are modulated by LAG-3. Lungs from C3-HA mice adoptively transferred with $10^{6}$ clone $4 \mathrm{CD}^{+}$cells were harvested 7 days after transfer, and cells were stimulated ex vivo. Wild-type clonotypic $\mathrm{CD}^{+}$cells failed to expand to appreciable levels in vivo (Figure 1B). Function of $\mathrm{CD}^{+}$cells was measured by intracellular staining of IFN- $\gamma$, and approximately $50 \%$ of wild-type clone $4 \mathrm{CD}^{+}$ cells isolated from lungs were IFN- $\gamma$ producing (Figure 1C). Thus, in this model of tolerance, $\mathrm{HA}$-specific $\mathrm{CD}^{+}$cells are still capable of functional responses 7 days after transfer, as opposed to HA-specific $\mathrm{CD}^{+}$cells that are fully tolerized 4 days after transfer (27).

We next treated mice with an $\alpha$ LAG- 3 antibody to determine whether any differences in clone $4 \mathrm{CD}^{+}$cell expansion could be detected in vivo. As described previously, the monoclonal $\alpha$ LAG-3 antibody does not lead to deletion of LAG-3-expressing $\mathrm{T}$ cells (20) and is thought to function by blocking LAG-3 interactions with MHC class II (28). C3-HA mice were adoptively transferred with clone $4 \mathrm{CD}^{+}$cells and given $\alpha$ LAG- 3 injections at the time of transfer and 3 days later, with lungs being harvested on day 7 . In contrast to untreated C3-HA mice, clone $4 \mathrm{CD} 8^{+}$cells expanded significantly in lungs of mice treated with $\alpha$ LAG-3 (Figure 1B), and their IFN- $\gamma$ production was greatly enhanced (Figure $1 \mathrm{C}$ ). While the $\alpha$ LAG- 3 antibody has been thought to block LAG-3 function, it is also possible that LAG-3 expression on $\mathrm{CD}^{+} \mathrm{T}$ cells is stimulatory and that the antibody acts as an agonist. Another question is whether the enhanced $\mathrm{CD}^{+}$accumulation and function upon in vivo $\alpha$ LAG-3 antibody treatment reflect functional effects on $\mathrm{CD}^{+} \mathrm{T}$ cells or are completely secondary to effects on endogenous $\mathrm{CD}^{+} \mathrm{T}$ cells (or other cells). In order to resolve these questions, we crossed the clone 4 TCR transgenic mice onto a LAG-3-/- background. Similar to wild-type clone $4 \mathrm{CD}^{+}$cells transferred into $\alpha$ LAG-3-treated mice, clone 4 LAG-3 $3^{-/}$mice expanded and produced large amounts of IFN- $\gamma$ (Figure 1, B and C). Cells from lungs were counted, and absolute numbers of clone 4 cells (Figure 1D) and IFN- $\gamma$-producing clone 4 cells (Figure 1E) were calculated. The 

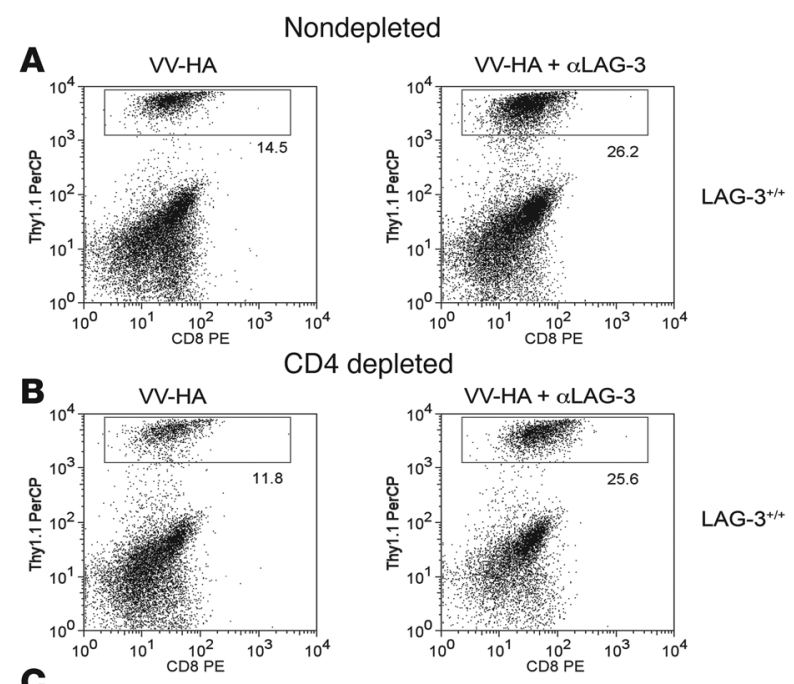

C
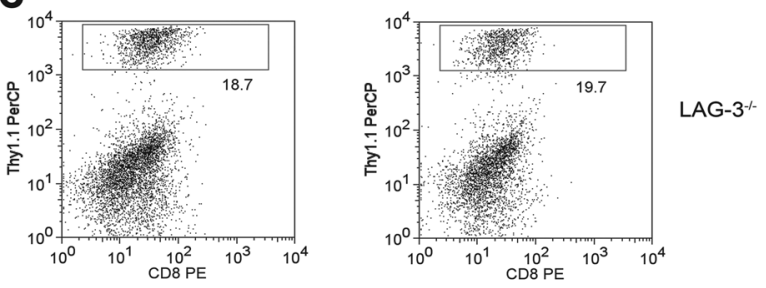

absolute number of cells mirrors the percentage of clonotypic cells found within the lungs of mice treated with $\alpha$ LAG-3. Overall, these results support the hypothesis that LAG-3 plays a direct inhibitory role on $\mathrm{CD}^{+} \mathrm{T}$ cells in the setting of self tolerance.

LAG-3 blockade enhances the number and effector function of specific $C D 8^{+} \mathrm{T}$ cells in mice with HA-expressing tumors. Since LAG-3 blockade was able to allow expansion of HA-specific CD8 ${ }^{+}$cells within the lungs of C3-HA mice, we next addressed whether the same would be true in a tumor-tolerizing environment. In many model systems, naturally arising autochthonous tumors induce tolerance among tumor-specific T cells, possibly utilizing mechanisms similar to those of peripheral self tolerance. We utilized ProHA $\times$ TRAMP mice that express HA as a prostate tumor-specific antigen in mature male mice. As previously described, Pro$\mathrm{HA} \times \mathrm{TRAMP}$ mice express both SV40 $\mathrm{T}$ antigen and HA in a prostate-restricted manner under the prostate-specific probasin promoter (29). HA-specific CD4 ${ }^{+} \mathrm{T}$ cells adoptively transferred into these tumor-bearing mice become functionally tolerant (29). Similar to the C3-HA mice, we adoptively transferred clone $4 \mathrm{CD}^{+} \mathrm{T}$ cells into mature 14- to 16 -week-old tumor-bearing ProHA $\times$ TRAMP mice. ProHA $\times$ TRAMP at 14 to 16 weeks mice typically have moderately well-differentiated tumors that are either nonmetastatic or that have metastasized locally to the draining lymph nodes (30). In contrast to the C3-HA mice, very few clone $4 \mathrm{CD}^{+} \mathrm{T}$ cells were observed in untreated animals 7 days after $T$ cell transfer (Figure $2 \mathrm{~B}$ ). However, significant effects of LAG-3 manipulation were observed on $\mathrm{CD}^{+} \mathrm{T}$ cells in the context of antigen-specific vaccination. ProHA $\times$ TRAMP mice were vaccinated with Vaccinia virus-HA (VV-HA) in combination with either LAG-3-blocking antibody or isotype control. Seven days after adoptive transfer, organs were harvested for analysis of $\mathrm{CD}^{+} \mathrm{T}$ cell accumulation as well as for $\mathrm{T}$ cell function analyzed via intracellular IFN- $\gamma$ staining. We first addressed

\section{Figure 4}

Cellular mechanism of $\alpha \mathrm{LAG}-3$ is independent of $\mathrm{CD} 4^{+}$cells but dependent on $\mathrm{CD}^{+}$in ProHA $\times$TRAMP prostate tissue. Intact or GK1.5-treated ProHA $\times$ TRAMP mice were injected with VV-HA or VV$\mathrm{HA} / \alpha \mathrm{LAG}-3$ as described and injected with $10^{6}$ (A and B) clone $4 \mathrm{CD}^{+}$ or (C) $\mathrm{LAG}_{-3^{-/-}}$clone 4 CD8 ${ }^{+}$cells i.v. Mice treated with GK1.5 were bled 1 day before transfer to confirm CD4 depletion. Seven days after cells were transferred, prostates were harvested and single-cell suspensions were prepared as described. Flow cytometry was performed on cells using $\mathrm{CD}^{+}$and Thy 1.1 antibodies to quantitate percentage of clonotypic cells. Results are representative of 3 experiments.

whether clone $4 \mathrm{CD}^{+}$cells were capable of LAG-3 expression in ProHA $\times$ TRAMP mice. Based on intracellular staining, clone 4 cells harvested from prostate tissue expressed LAG-3 (Figure 2A). LAG-3 surface staining on clone $4 \mathrm{CD}^{+}$cells from prostate tissue was not as apparent as LAG-3 staining from lungs of C3-HA mice (Figure 1A). This may be due to the presence of multiple proteases found within prostate tissue. LAG-3 is also cleaved at the cell surface by metalloproteinases, contributing to its downregulation (31). VV-HA vaccination of ProHA $\times$ TRAMP mice that were adoptively transferred with clone $4 \mathrm{CD}^{+}$cells resulted in an accumulation of $\mathrm{CD}^{+} \mathrm{T}$ cells in the prostate gland. These cells divided and produced IFN- $\gamma$ in the tumor-bearing prostate glands (Figure 2, B and C) but failed to provide any detectable antitumor effect (see below). Prostates from ProHA $\times$ TRAMP animals treated with $\alpha$ LAG- 3 alone did not accumulate clone $4 \mathrm{CD}^{+}$cells and looked similar to those of untreated animals (data not shown). Combining HA-specific vaccination with $\alpha$ LAG-3 blockade resulted in a significantly increased frequency of IFN- $\gamma$-producing HA-specific $\mathrm{CD}^{+} \mathrm{T}$ cells in the prostate glands of ProHA $\times$ TRAMP mice (Figure 2, B and C).

Absolute numbers of prostate-derived clone $4 \mathrm{CD}^{+}$cells (Figure 2D) and IFN- $\gamma$-producing clone $4 \mathrm{CD}^{+}$cells (Figure 2E) were calculated by pooling prostates and demonstrated a significantly higher number of cells after combined VV-HA/ $\alpha$ LAG-3 treatment as compared with VV-HA alone. To confirm the antibody blockade data, clone $4 \mathrm{CD} 8^{+} \mathrm{LAG}^{-3^{-/}}$cells were adoptively transferred into VV-HA-treated ProHA $\times$ TRAMP mice. Seven days after transfer, prostates were harvested and single-cell suspensions stimulated in vitro. These results indicate that LAG-3-1$\mathrm{CD}^{+}$cells are able to accumulate in prostates similarly to clone 4 $\mathrm{CD}^{+}$cells treated with $\alpha$ LAG-3 plus VV-HA (Figure 2, B and C).

We addressed whether the increased $\mathrm{CD}^{+} \mathrm{T}$ cell accumulation noted in ProHA $\times$ TRAMP mice vaccinated in the presence of LAG-3-blocking antibody was specific for the prostate, where $\mathrm{HA}$ is expressed. As expected, $\mathrm{CD}^{+} \mathrm{T}$ cells activated by vaccination showed slightly increased trafficking to non-antigen expressing organs (Figure 2F). However, LAG-3 blockade did not result in further increased accumulation of clonotypic $\mathrm{CD}^{+} \mathrm{T}$ cells in the liver, lungs, or spleen (Figure $2 \mathrm{~F}$ ), organs that do not express HA in the ProHA $\times$ TRAMP mice (29). Accumulation of HA-specific clone $4 \mathrm{CD}^{+}$cells only occurred in HA-bearing prostates (Figure $2 \mathrm{~F}$ ). These data show that combining LAG-3 blockade with vaccination does not result in nonspecific accumulation of clonotypic $\mathrm{CD}^{+} \mathrm{T}$ cells; rather, $\mathrm{CD}^{+} \mathrm{T}$ cells accumulate at sites of antigen expression.

Visualization of clone $4 \mathrm{CD}^{+}$cells within prostate tissue after LAG-3 blockade. To determine the anatomical localization of the clone $4 \mathrm{CD}^{+} \mathrm{T}$ cells that accumulate in ProHA $\times$ TRAMP prostates 

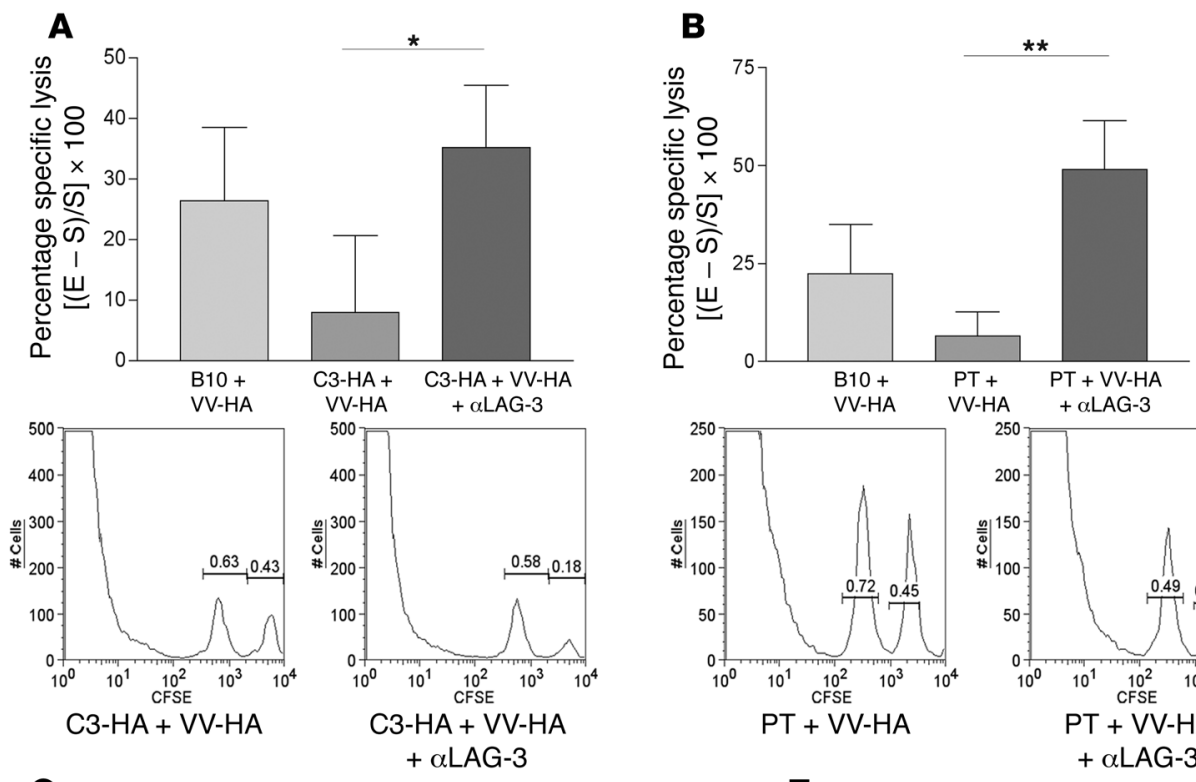

C

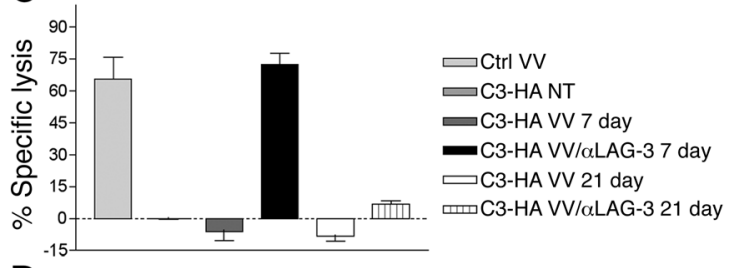

D

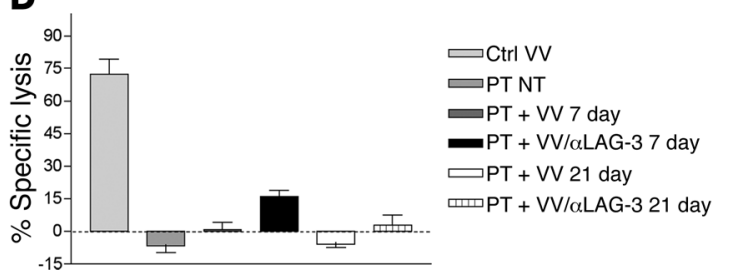

\section{Figure 5}

Self- and tumor-tolerized endogenous CTLs regain effector function in vivo after treatment with $\mathrm{VV}-\mathrm{HA} /$ $\alpha$ LAG-3. (A) C3-HA and (B) ProHA $\times$ TRAMP mice were given $0.2 \mathrm{mg}$ $\alpha$ LAG-3 i.p. on days 0 and 3 and $10^{6}$ PFUs of VV-HA i.p. on day 1. Mice received target cells i.v. consisting of a 1:1 mixture of B10.D2 splenocytes loaded with either HA peptide plus $5 \mathrm{mM}$ CFSE or $0.5 \mathrm{mM}$ CFSE only on day 6 . Eighteen hours after target transfer, spleens were harvested for flow cytometry. Histograms under each graph represent 1 of 5 individual mice from 1 experiment. Data represent 1 experiment with each being repeated at least 2 times. ${ }^{*} P=0.0378 ;{ }^{* \star} P=0.0171$. In vivo CTL assays were performed as above with the addition of groups that were transferred with target cells 21 days after immunization with VV-HA or VV-HA plus $\alpha$ LAG-3 (C and D). (E) Seven-week-old ProHA $\times$ TRAMP mice were injected with $\alpha$ LAG-3, VV-HA, or VV-HA/ $\alpha$ LAG-3 or left untreated ( $n=15$ mice/group). Eight weeks later, dorsal prostate lobes were harvested and H\&E sections prepared. Slides were graded on a scale from $0-5$ as described in Methods in a double-blinded fashion by 2 surgical pathologists. PT, ProHA $\times$ TRAMP. after treatment with $\alpha$ LAG-3, we performed histological and immunohistochemical analysis of the prostate glands of mice treated with $\alpha$ LAG-3 in the presence or absence of vaccination. For these studies, animals were harvested 7 days after adoptive $\mathrm{CD}^{+}$ $\mathrm{T}$ cell transfer, with one lobe harvested for histological analysis (Figure 3, A and B) and the other lobe used for the flow cytometric analyses as in Figure 2. H\&E-stained sections from nontreated and $\alpha$ LAG-3-treated mice were similar, showing an absence of lymphocytic infiltration, an intact stroma, and no obvious disruption of the glandular epithelium (Figure 3A). Vaccine-treated mice showed moderate lymphocytic infiltration, and the glandular epithelium remained grossly intact (Figure 3A). Mice vaccinated in the presence of LAG-3 blockade showed lymphocytic infiltration as well, but in contrast to mice that received vaccine alone, a cellular infiltrate was observed within the lumen of many of the glandular structures (Figure $3 \mathrm{~A}$ ). In addition, mice treated with the vaccine in combination with LAG-3 blockade showed significant disruption of the glandular epithelial cell layer (Figure 3A). To determine whether the lymphocytic infiltrate was composed of adoptively transferred or endogenous cells, we performed immunofluorescence staining for the congenic marker Thy1.1, which marks transferred clone $4 \mathrm{~T}$ cells (Figure $3 \mathrm{~B}$ ). In untreated or $\alpha$ LAG-3-treated ProHA $\times$ TRAMP mice there was no observable infiltration of Thy $1.1^{+}$clone $4 \mathrm{CD}^{+}$cells (data not shown). In mice treated with vaccine alone, prostate-specific $\mathrm{CD}^{+} \mathrm{T}$ cells accumulated at the epithelial cell layer but did not penetrate into the glandular lumen (Figure 3B). However, when vaccination was performed in conjunction with LAG-3 blockade, these clonotypic HAspecific $\mathrm{CD}^{+} \mathrm{T}$ cells infiltrated into the luminal space (Figure $3 \mathrm{~B}$ ). Flow cytometry of prostates from these experiments supported the histological data (Figure $3 \mathrm{C}$ ). Thus, vaccination of ProHA $\times$ TRAMP mice in the presence of LAG-3 blockade increased effector $\mathrm{CD}^{+} \mathrm{T}$ cell accumulation in the prostate gland and resulted in anatomical disruption of glandular architecture. Similarly, in C3-HA mice adoptively transferred with clone 4 wild-type CD8 ${ }^{+}$ cells or LAG-3-/-CD8 ${ }^{+} \mathrm{T}$ cells, accumulation of lymphocytes could be visualized in the alveolar space, with more LAG-3-/- cells present than wild-type (Supplemental Figure 3).

$C D 4^{+} T$ cells are not required for LAG-3-blocking antibody function. Our data using $\mathrm{LAG}^{-3^{-/}}$clone $4 \mathrm{CD}^{+} \mathrm{T}$ cells suggested a cellintrinsic effect of LAG-3 on CD8 ${ }^{+} \mathrm{T}$ cells (Figures 1 and 2). To further assess whether LAG-3 played a direct role on $\mathrm{CD}^{+} \mathrm{T}$ cells, we asked whether $\mathrm{CD} 4^{+}$cells were necessary for the increased accumulation of clone $4 \mathrm{CD}^{+}$cells in ProHA $\times$TRAMP prostates after treatment with $\alpha$ LAG- 3 and VV-HA. This was accomplished by depleting ProHA $\times$ TRAMP mice of $\mathrm{CD}^{+}{ }^{+} \mathrm{T}$ cells using the $\mathrm{CD} 4^{+}-$ 
depleting GK1.5 antibody. Once more than 95\% CD4 ${ }^{+}$depletion was confirmed (data not shown), clone $4 \mathrm{CD}^{+} \mathrm{T}$ cells were adoptively transferred and animals treated with either vaccination or the combination of vaccination and $\alpha$ LAG-3. As described above, the combination of LAG-3 blockade and vaccination resulted in increased accumulation of $\mathrm{CD}^{+} \mathrm{T}$ cells in the prostate gland (Figure 4A). LAG-3 blockade also increased $\mathrm{T}$ cell accumulation in the prostate gland of $\mathrm{CD}^{+}$-depleted animals (Figure 4B), supporting a $\mathrm{CD}^{+} \mathrm{T}$ cell-intrinsic function. However, LAG-3/- clone $4 \mathrm{CD}^{+} \mathrm{T}$ cells showed no differences in organ-specific accumulation when treated with $\alpha$ LAG-3-blocking antibody in combination with vaccination (Figure 4C). Taken together, these data provide substantial evidence that, in this system, LAG-3 plays a direct role on $\mathrm{CD}^{+} \mathrm{T}$ cells independent of its role on $\mathrm{CD} 4^{+}$cells.

LAG-3 blockade restores the CTL activity of endogenous $C D 8^{+} T$ cells. Since we observed an increase in IFN- $\gamma$-producing antigen-specific $\mathrm{CD}^{+} \mathrm{T}$ cells in both C3-HA mice (Figure 1) and ProHA $\times$ TRAMP mice (Figure 2 ) treated with $\alpha$ LAG-3 antibodies, we next sought to determine whether the cytolytic function of endogenous $\mathrm{CD}^{+} \mathrm{T}$ cells could be enhanced by $\alpha$ LAG -3 treatment. To test this, we utilized an in vivo CTL assay (32) to measure the ability of endogenous $\mathrm{CD}^{+}$cells to lyse adoptively transferred targets loaded with HA class I peptide. Nontransgenic B10.D2 mice responded to vaccination with $20 \%$ lysis of HA-loaded targets when normalized to nonvaccinated B10.D2 mice. As previously described, C3-HA mice are tolerant to HA (33). Indeed, vaccination of these mice failed to elicit a significant in vivo CTL response (Figure 5A). However, when these mice were vaccinated in the presence of LAG-3-blocking antibody, CTL tolerance was significantly mitigated; approximately $30 \%$ specific lysis was observed. We next determined whether LAG-3 blockade could affect CTL tolerance to a tumor/tissue-restricted antigen in the ProHA $\times$ TRAMP mice. Similar to C3-HA mice, vaccination of ProHA $\times$ TRAMP mice failed to elicit a significant CTL response in vivo (Figure $5 \mathrm{~B}$ ). However, vaccination in the context of LAG-3 blockade significantly reversed this functional tolerance, with approximately $45 \%$ specific target lysis noted.

In order to evaluate the durability of the combined VV-HA/ $\alpha$ LAG-3 treatment, we examined CTL function of endogenous, tolerized $\mathrm{CD}^{+}$cells from C3-HA (Figure 5C) and ProHA $\times$ TRAMP (Figure 5D) mice at 7 days and 21 days after VV-HA treatment with or without $\alpha$ LAG-3. Dramatically, 21 days after VV-HA plus $\alpha$ LAG-3 treatment, endogenous CTL function decreased precipitously compared with 7 days after VV-HA treatment, although there was still detectable lysis of target cells. These results were repeatable in both our self-tolerance and tumortolerance models. Overall, this intriguing finding suggests that reversal of LAG-3-dependent $\mathrm{CD}^{+}$inhibition is short-lived. This has important translational implications, namely that repeated injections of $\alpha$ LAG-3 might be necessary to achieve sustained cellular activation. Thus, LAG-3 blockade mitigated endogenous CTL tolerance to HA regardless of whether this protein was widely expressed as a self antigen or expressed in a narrower tumor/tissue-specific manner.

Treatment with $\alpha L A G$-3-blocking antibody delays outgrowth of autochthonous ProHA $\times$ TRAMP tumors. ProHA $\times$ TRAMP mice develop prostatic intraepithelial neoplasia (PIN) at approximately 10 weeks of age due to the expression of SV40 T antigen under control of the probasin promoter (29). Over the next several weeks, mice develop progressive adenocarcinoma with a mean mortality of 35 weeks on the B10.D2 background. Since endogenous, tolerized $\mathrm{CD}^{+} \mathrm{T}$ cells regain functional activity when animals are vaccinated in combination with LAG-3 blockade (Figure 5, B and D), we determined whether early intervention with this combination could delay the outgrowth of endogenous tumors. Young (7-9 weeks) ProHA $\times$ TRAMP mice were vaccinated in either the presence or absence of LAG-3-blocking antibody. Eight weeks after treatment (when mice were approximately 16 weeks of age) dorsal prostate glands were harvested and $\mathrm{H} \& \mathrm{E}$ sections obtained. Two surgical pathologists scored these sections in a blinded manner. As shown in Figure 5E, combined treatment resulted in a statistically significant reduction of tumor grade. Surprisingly, LAG-3 treatment alone also resulted in grade reduction, although to a lesser degree than that seen with the combination regimen. Overall, these data suggest that the reversal of CTL functional tolerance mediated by LAG-3 blockade can delay tumor progression in vivo, a significant finding in this autochthonous tumor model in which every cell is persistently driven to a malignant state via expression of SV40 T antigen. Interestingly, we also found increased LAG-3 expression in human prostate-infiltrating CD8 ${ }^{+}$ $\mathrm{T}$ cells as compared with $\mathrm{CD} 8^{+} \mathrm{T}$ cells isolated from peripheral blood (Supplemental Figure 4).

\section{Discussion}

LAG-3, an Ig superfamily member, negatively regulates murine $\mathrm{T}$ cell activation $(28,34)$ and homeostasis $(23)$. While previous data provide abundant evidence for LAG-3 in regulating these pathways, the intrinsic function of LAG- 3 on $\mathrm{CD}^{+} \mathrm{T}$ cells has not been established. Here, we utilized HA-specific TCR transgenic $\mathrm{CD}^{+} \mathrm{T}$ cells (clone 4) to examine the role of LAG-3 in tolerance to self- and tumor-restricted antigen. In the self-antigen system, clone $4 \mathrm{CD}^{+} \mathrm{T}$ cells were adoptively transferred to mice that highly expressed HA in multiple epithelial organs (C3-HA). In the tumor-antigen setting, we utilized mice that expressed HA in conjunction with spontaneously evolving prostate tumors (ProHA $\times$ TRAMP). Remarkably, we found that combined VV-HA and $\alpha$ LAG-3 treatment reversed antigen-specific CTL unresponsiveness and significantly increased the accumulation of tumor-specific effector CTLs at the sites of antigen. Similar findings using LAG-3-- clone $4 \mathrm{CD}^{+} \mathrm{T}$ cells support the notion that LAG-3 plays a direct inhibitory role on $\mathrm{CD}^{+} \mathrm{T}$ cells and that the $\alpha \mathrm{LAG}-3$ antibody functions as an antagonist. Clone $4 \mathrm{CD}^{+}$cells have a high affinity for the HA antigen (35) and thus may not fairly represent the repertoire of tumor-associated antigen-specific $T$ cells present in the endogenous $\mathrm{T}$ cell pool, such as have been isolated from patients with prostate cancer and stimulated to become reactivated against their cognate antigen $(36,37)$. However, the results of our in vivo CTL assay in both C3-HA and ProHA $\times$ TRAMP mice demonstrate the capacity of $\alpha$ LAG- 3 antibodies to reverse tolerance in the endogenous T cell pool, since no TCR transgenic $\mathrm{T}$ cells were transferred for those experiments.

$\mathrm{T}$ cells are essential for the control of tumor development and progression (38); however, multiple mechanisms, both tumor derived and host derived, can impair tumor-specific immune responses (39). Tumor-specific $\mathrm{CD}^{+} \mathrm{T}$ cells are exquisitely sensitive to such mechanisms, including Treg-dependent suppression mediated through TGF- $\beta(40-42)$. Therefore, overcoming the inhibitory pressure on tumor-specific $\mathrm{CD}^{+}$cells mediated by Tregs and tumors may allow successful elimination of established tumors. Several costimulatory molecules, including PD-1 
(43) and possibly CTLA-4 (12), negatively regulate the expansion and effector function of activated CTLs. Our results are indeed somewhat analogous to those observed when function of chronically exhausted $\mathrm{CD}^{+} \mathrm{T}$ cells was restored after treatment with PD-L1 blockade (16). In this model, lymphocytic choriomeningitis virus-specific (LCMV-specific) $\mathrm{CD}^{+} \mathrm{T}$ cells from chronically infected LCMV mice are unable to proliferate, produce effector cytokines, lyse LCMV-infected cells, or control viral load. However, in vivo blockade of PD-1:PD-L1 interactions reverses the functionally impaired $\mathrm{CD} 8^{+} \mathrm{T}$ cells, resulting in a decreased viral load. Overall, these results suggest that costimulatory blockade can significantly affect the functional characteristics of $\mathrm{CD}^{+} \mathrm{T}$ cells.

ProHA $\times$ TRAMP mice express HA as a tumor-associated antigen only within the prostate tissue of male mice (29). In this autochthonous tumor model, adoptively transferred clone $4 \mathrm{CD}^{+}$cells do not traffic to the prostates, nor are they present in significant numbers in the lymphoid organs after 7 days (Figure 2). Interestingly, expression of LAG-3 on clone $4 \mathrm{CD}^{+}$cells within prostates of VV-HA-treated mice was limited to intracellular stores (Figure 2A); however, treatment with $\alpha$ LAG-3 robustly increased the frequency of clonotypic cells (Figure 2B). This situation is similar to that of CTLA-4, where surface expression on lymphocytes can be difficult to detect while intracellular protein is clearly evident. In keeping with the highly selective expression of HA in ProHA $\times$ TRAMP mice, it does not appear as if the HA-specific T cells are thymically deleted in these animals, since crossing clone 4 TCR transgenic mice to ProHA $\times$ TRAMP mice results in similar numbers of clone $4 \mathrm{CD}^{+}$cells in the double transgenic as in the single TCR transgenic as late as 30 weeks (data not shown). Treatment of ProHA $\times$ TRAMP mice adoptively transferred with clone $4 \mathrm{CD}^{+}$cells with VV-HA, however, results in the expansion of effector clone $4 \mathrm{CD}^{+}$ cells within the prostate tissue. Similar to other findings (44), we observed that after VV-HA treatment, clone $4 \mathrm{CD}^{+}$cells were present within the prostate epithelia; however, there did not seem to be an associated tissue disruption or cell death. This suggests that clone $4 \mathrm{CD}^{+}$cells accumulate within the transformed prostate epithelium but fail to eradicate tumor cells. These data are consistent with previous experiments suggesting that $\mathrm{CD}^{+}$cells can home and proliferate within tumor sites but fail to perform cytolytic function $(40,41)$. Interestingly, injection of $\alpha$ LAG-3 along with VV-HA led to an enhanced accumulation of effector clone $4 \mathrm{CD}^{+} \mathrm{T}$ cells within the prostate tissue. Similar results were obtained using clone $4 \mathrm{CD} 8^{+} \mathrm{LAG}^{-3^{-/}}$T cells plus VV-HA. Indeed, the histology and immunohistochemistry of prostate tissue from VV-HA plus $\alpha$ LAG-3-treated mice was strikingly different from that of VV-HA-treated prostates. After treatment with $\alpha$ LAG-3 plus VV-HA, clone $4 \mathrm{CD}^{+}$cells were found within the lumen of the prostates and the stroma of the glands was disrupted. These results suggest that not only does LAG-3 blockade allow clone $4 \mathrm{CD}^{+} \mathrm{T}$ cells to accumulate at higher numbers within the prostates but also that the CTLs are functionally competent. Since LAG-3 negatively regulates T cell homeostasis (23), it is possible that blockade of LAG-3 function allows the expansion of adoptively transferred clone $4 \mathrm{CD} 8^{+}$cells in an antigen-independent fashion. However, clone $4 \mathrm{CD}^{+}$cells accumulated only in prostate tissue and not in liver tissue after either VV-HA or VV-HA plus $\alpha$ LAG-3 treatments, demonstrating that the enhanced effect was specific to tissues expressing the cognate antigen. These results suggest that LAG-3 blockade allows accumulation of antigen-specific $\mathrm{CD}^{+}$cells only where antigen is present and does not promote antigen-independent homeostatic expansion of the transferred cells.

Since endogenous tumor-specific CTL function was restored in VV-HA plus $\alpha$ LAG-3-treated mice, we wished to determine whether this combined treatment affected tumor incidence in ProHA $x$ TRAMP mice. We chose a treatment scheme that would expand and activate HA-specific T cells before the onset of tumorigenesis, thus allowing for the generation of tumor-specific memory $\mathrm{T}$ cells in the absence of malignancy. This treatment scheme did not involve further boosting of $\mathrm{T}$ cell immunity after the initial priming. Interestingly, our results indicate a slight, yet significant effect of tumor progression after treatment with $\alpha$ LAG-3 or VV-HA plus $\alpha$ LAG- 3 compared with untreated control mice based on the grading of histological sections of dorsal prostate tissue. Further experiments utilizing prime boosts, greater doses, and more sustained treatment with $\alpha$ LAG- 3 are being performed to determine whether ProHA $\times$ TRAMP tumors can be further abrogated.

The reversal of $\mathrm{CD}^{+}$functional unresponsiveness by LAG-3 blockade may be the result of several mechanisms. We previously demonstrated LAG-3 expression on CD $4^{+} \mathrm{CD} 25^{+}$Tregs and have shown that antibody blockade of LAG-3 results in impaired function of these Tregs in vivo (20). It is therefore plausible that $\alpha$ LAG-3 treatment is inhibiting function of Tregs, thus allowing CTL function. Tregs $\left(\mathrm{CD} 4^{+} \mathrm{CD} 25^{+} \mathrm{FoxP}^{+}\right)$have been shown to influence $\mathrm{CD}^{+} \mathrm{T}$ cell effector function in vivo $(40,45)$. In addition, we previously showed that LAG-3-expressing $\mathrm{CD}^{+} \mathrm{T}$ cells could mediate regulatory function in vivo and in vitro (20). No detectable differences in Treg frequencies or absolute number were noted in any of these treatment groups, nor did LAG-3 effect expression of FoxP3 within $\mathrm{CD}^{+}$cells (data not shown), though our previous studies showed that LAG-3 blockade mitigates Treg function. The findings in this study, that antibody treatment altered the local accumulation of antigen-specific $\mathrm{CD}^{+} \mathrm{T}$ cells in $\mathrm{CD}^{+}$-depleted animals, demonstrate that in the ProHA $\times$ TRAMP system, LAG-3 blockade affects $\mathrm{CD}^{+} \mathrm{T}$ cell function in part by a mechanism independent of conventional $\mathrm{CD}^{+}$Tregs. Further studies will be necessary to dissect the differential roles of LAG- 3 on $\mathrm{CD}^{+}{ }^{+}$vs. $\mathrm{CD}^{+} \mathrm{T}$ cells as well as the molecular mechanism of negative regulation mediated by LAG-3. Clearly, the demonstration of its inhibitory role on both $\mathrm{CD}^{+}$ (18) and $\mathrm{CD}^{+} \mathrm{T}$ cells (this manuscript) demonstrates a broad regulatory function for LAG-3.

Tumor-associated antigen-based vaccines are becoming widely accepted as a unique and powerful method for the treatment of many types of cancers (46). Moderate success in generating robust long-lasting tumor-specific $\mathrm{CD}^{+} \mathrm{T}$ cell responses has been achieved albeit with varying degrees of success demonstrating significant alterations in time to disease progression (47-49). Here, we have demonstrated a reversal of functionally unresponsive antigen-specific $\mathrm{CD}^{+} \mathrm{T}$ cells in murine models of self and tumor tolerance after combined treatment with a viral vaccine and antibody-mediated LAG-3 blockade. The durability of the $\alpha$ LAG-3 treatment seems short-lived (Figure 5, C and D); therefore multiple doses over time may be required to sustain $\mathrm{CD}^{+} \mathrm{T}$ cell function. Overall, we show for what we believe is the first time a direct role for LAG-3 on CD8 ${ }^{+} \mathrm{T}$ cells in models of self and tumor tolerance. From a clinical perspective, LAG-3 has previously been shown to be upregulated on tumor-infiltrating $\mathrm{CD}^{+} \mathrm{T}$ cells isolated from multiple human tumor types (50). We show here that this applies 
to prostate cancer as well (Supplemental Figure 4). Taken together, these results suggest that LAG-3 may be a promising target for promoting tumor immunity.

\section{Methods}

Mice, cell lines, antibodies, and vaccines. Recipient mice (B10.D2 [Thy1.2 $\left.{ }^{+}, \mathrm{H}-2^{\mathrm{d}}\right]$ ), were obtained from The Jackson Laboratory. C3-HA (C3-HA hi; Thy1.2 ${ }^{+}$, HA expression on multiple tissues) and ProHA $\times$ TRAMP (Thy1.2+ ${ }^{+}$HA and SV-40 expression is prostate specific) mice on the B10.D2 background were described previously (29). Donor mice (clone 4 TCR transgenic [Thy $1.1^{+}, \mathrm{K}^{\mathrm{d}}$; HA-specific]) mice were provided by L. Sherman (The Scripps Research Institute, La Jolla, California, USA). C57BL/ 6 LAG-3 $3^{-/-}$mice and the $\alpha$ LAG-3producing hybridoma (C9B7w) were kind gifts from D. Vignali (St. Jude Children's Research Hospital, Memphis, Tennessee, USA). LAG-3-/- mice were crossed with B10.D2 clone 4 mice for at least 10 generations. Animal care and experimental procedures were performed under pathogen-free conditions under a specific animal protocol reviewed by and approved by the Institutional Animal Care and Use Committee of Johns Hopkins University. Recombinant vaccinia virus expressing wild-type HA protein (VV-HA) was used in vaccination strategies and was created as described previously (29).

In vivo CTL assay. As previously described (32), splenocytes from nontransgenic B10.D2 mice were isolated and split into 2 groups. Group 1 was left untreated, while group 2 was loaded with synthetic immunodominant HA class I peptide (IYSTVASSL) at a concentration of $10 \mu \mathrm{g} / \mathrm{ml}$, then washed 3 times, counted, and resuspended. Group 1 cells were then labeled as CFSE $^{\text {lo }}$ and group 2 as CFSE ${ }^{\text {hi }}$ by incubation with $0.25 \mathrm{mM}$ or $2.5 \mathrm{mM}$ CFSE, respectively. After labeling, cells were thoroughly washed with HBSS and counted. An equal number of HA-loaded CFSE ${ }^{\text {hi }}$ and unloaded CFSE ${ }^{\text {lo }}$ target cells were combined and administered by tail-vein injection. Eighteen hours after target cell transfer, splenocytes from recipient mice were analyzed by FACS, and the relative cell numbers in CFSE $^{\text {hi }}$ versus CFSE $^{\text {lo }}$ peaks were determined to quantify percentage of specific lysis. Representative examples of acquired data are shown in Figure 5A.

Adoptive transfers. For adoptive transfer experiments, clone 4 mice were sacrificed via $\mathrm{CO}_{2}$ asphyxiation. Spleens and lymph nodes were collected and homogenized, and red blood cells were lysed. $\mathrm{CD}^{+} \mathrm{T}$ cells were purified using Miltenyi magnetically labeled beads (Miltenyi Biotec) according to the manufacturer's protocol. For some experiments, purified cells were labeled for 8 minutes with CFSE (Invitrogen) by adding $0.5 \mu \mathrm{l}$ of $5 \mathrm{mM}$ stock per $1 \mathrm{ml}$ cells. After labeling, cells were washed twice and resuspended with HBSS for i.v. injections. Typically, $10^{6}$ cells were injected per mouse in $0.2 \mathrm{ml}$ HBSS by tail-vein injection.

GK1.5 treatment. For $\mathrm{CD}^{+}$depletion experiments, mice were treated with GK1.5 ascites (kindly provided by E. Jaffee, Johns Hopkins University) 3 and 5 days prior to adoptive transfer with clone $4 \mathrm{CD}^{+}$or clone 4 $\mathrm{CD}^{+} \mathrm{LAG}^{-3^{-/}}$cells. To assess $\mathrm{CD}^{+}$status, tail blood was taken 1 day prior to adoptive transfer. In all cases, mice had more than 95\% CD4 depletion prior to transfer and at the time of organ harvests.

Quantification of $H A$-specific $C D 8^{+} T$ cell responses. On day 7 after adoptive transfer, recipient mice were sacrificed via $\mathrm{CO}_{2}$ asphyxiation. The spleen, axillary lymph nodes, and prostate-draining lymph nodes were dissected, dissociated, and washed (26). To obtain tumor- or tissue-infiltrating lymphocytes, mice were surgically exsanguinated (51), and the lungs and prostate glands were microdissected (52). Tissues were mechanically disrupted and incubated for 1 hour at $37^{\circ} \mathrm{C}$ with CTL media containing the enzyme liberase (Roche Applied Science) at a final concentration of $35 \mu \mathrm{g} / \mathrm{ml}$. Lymphocytes were isolated from the digestion product using Ficoll-Hypaque gradient centrifugation. For FACS analysis, $10^{6}$ lymphocytes from the spleen or the lymph nodes, or $10^{6}$ prostate-infiltrating lymphocytes were stained using anti-Thy1.1 antibody and anti-CD8 antibody (BD Bioscienc- es - Pharmingen). Cells were analyzed using a FACSCalibur system (BD). Lymphocytes from prostate samples generally have lower expression of CD8 compared with $\mathrm{CD}^{+}$cells taken from other sites. This effect may be due to treatment of cells with Liberase as well as the presence of various proteases found within prostate tissue. Intracellular staining for LAG-3 or IFN- $\gamma$ was performed as previously described (13). In brief, $10^{6}$ lymphocytes were incubated with synthetic immunodominant HA class I peptide (IYSTVASSL) and $5 \mu \mathrm{g} / \mathrm{ml}$ monensin for 5 hours in vitro. Cells were stained with cellsurface antibodies, fixed, and permeabilized using Cytofix/Cytoperm Plus Kit (BD Biosciences - Pharmingen), followed by staining with anti-LAG-3, anti-IFN- $\gamma$ (BD Biosciences - Pharmingen), or anti-FoxP3 (eBiosciences).

Pathology and immunohistochemistry. To evaluate potential glandular architecture disruption induced by LAG-3 blockade, dorsal lobes were harvested as described above and frozen in OCT (Sakura). Serial unstained and H\&E sections from the dorsal prostate lobes were then cut. Two surgical pathologists evaluated H\&E sections for glandular disruption in a double-blinded manner. Prostate histology was scored on a scale of $0-5$ as follows: 0 , no benign tissue; 1 , PIN without cribriform formation; 2, PIN plus cribriform formations; 3 , intraductal carcinoma; 4, moderately differentiated carcinoma; 5, poorly differentiated carcinoma/small cell carcinoma.

For immunohistochemistry of Thy 1.1, unstained slides were fixed in $75 \%$ acetone $/ 25 \%$ ethanol for 5 minutes. Dry slides were washed $3 \times$ in PBS, followed by a 30-minute incubation with Image-iT FX signal enhancer (Molecular Probes). Slides were washed in PBS and blocked with Avidin/Biotin Block (Vector Laboratories). Slides were then incubated with $\alpha$ Thy1.1-biotin for 45 minutes, washed, then incubated with Alexa Fluor 488 Streptavidin for 30 minutes. Slides were then imaged on a fluorescent microscope.

Isolation of human prostatic $C D 8^{+}$cells. Needle aspirates were obtained from the peripheral zone of the prostate within 1 hour after radical prostatectomy using a 20G 11/2 needle and 5-cc syringe and collected into RPMI 1640 medium. Cells were spun down, resuspended in $1 \mathrm{ml}$ of Dynal Buffer 1 (Invitrogen), and strained through a $100-\mu \mathrm{m}$ strainer. CD8 ${ }^{+} \mathrm{T}$ cells were positively isolated using a Dynal CD8 Positive Isolation Kit (Invitrogen) according to the manufacturer's recommended protocol, including magnetic bead detachment. Cells were then resuspended in $1 \mathrm{ml} 1 \times$ staining buffer. Cells were stained with anti-CD8, anti-CD3 (BD Biosciences - Pharmingen), and anti-LAG-3 (Alexis Biochemicals).

Statistics. $P$ values were calculated using 2 -tailed Student's $t$ test, as implemented in the Prism 4.0 package (GraphPad Software).

\section{Acknowledgments}

We thank Bonnie Gambichler and Dallas Flies for technical assistance and Dario Vignali and Creg Workman for insightful comments. We also thank Karen Sfanos and William Issacs for human prostate samples and staining and LiJie Zhen for preparation of lungs for histology. C.G. Drake is a Damon Runyon-Lilly clinical investigator. D.M. Pardoll holds the Seraph Chair for Cancer Research. This work was also supported by NIH grant CA096948 (to C.G. Drake) and gifts from William and Betty Topercer, Dorothy Needle, Jack Goldsmith, and the Janey Fund.

Received for publication December 8, 2006, and accepted in revised form July 25, 2007.

Address correspondence to: Charles G. Drake, Johns Hopkins University School of Medicine, 1650 Orleans Street, CRB 452, Baltimore, Maryland 21231, USA. Phone: (410) 502-7523, Fax: (410) 614-0549; E-mail: drakech@jhmi.edu. 
1. Croft, M. 2003. Co-stimulatory members of the TNFR family: keys to effective T-cell immunity? Nat. Rev. Immunol. 3:609-620

2. Dong, C., Nurieva, R.I., and Prasad, D.V. 2003. Immune regulation by novel costimulatory molecules. Immunol. Res. 28:39-48.

3. Khoury, S.J., and Sayegh, M.H. 2004. The roles of the new negative $T$ cell costimulatory pathways in regulating autoimmunity. Immunity. 20:529-538.

4. Wang, S., and Chen, L. 2004. Co-signaling molecules of the B7-CD28 family in positive and negative regulation of $\mathrm{T}$ lymphocyte responses. Microbes Infect. 6:759-766.

5. Greenwald, R.J., Freeman, G.J., and Sharpe, A.H. 2005. The B7 family revisited. Annu. Rev. Immunol. 23:515-548

6. Del Rio, M.L., et al. 2005. Antibody-mediated signaling through PD-1 costimulates T cells and enhances CD28-dependent proliferation. Eur. J. Immunol. 35:3545-3560.

7. Shin, T., et al. 2005. In vivo costimulatory role of B7-DC in tuning T helper cell 1 and cytotoxic T lymphocyte responses. J. Exp. Med. 201:1531-1541.

8. Tivol, E.A., et al. 1995. Loss of CTLA-4 leads to massive lymphoproliferation and fatal multiorgan tissue destruction, revealing a critical negative regulatory role of CTLA-4. Immunity. 3:541-547.

9. Waterhouse, P., et al. 1995. Lymphoproliferative disorders with early lethality in mice deficient in Ctla-4. Science. 270:985-988

10. Blank, C., et al. 2003. Absence of programmed death receptor 1 alters thymic development and enhances generation of CD4/CD8 double-negative TCRtransgenic T cells. J. Immunol. 171:4574-4581.

11. Metz, D.P., Farber, D.L., Taylor, T., and Bottomly, K. 1998. Differential role of CTLA-4 in regulation of resting memory versus naive $\mathrm{CD} 4 \mathrm{~T}$ cell activation. J. Immunol. 161:5855-5861.

12. Gajewski, T.F., Fallarino, F., Fields, P.E., Rivas, F., and Alegre, M.L. 2001. Absence of CTLA-4 lowers the activation threshold of primed CD8+ TCR transgenic T cells: lack of correlation with $\mathrm{Src}$ homology domain 2-containing protein tyrosine phosphatase. J. Immunol. 166:3900-3907.

13. Goldberg, M.V., et al. 2007. Role of PD-1 and its ligand, B7-H1, in early fate decisions of CD8 T cells. Blood. 110:186-192.

14. Tsushima, F., et al. 2007. Interaction between B7$\mathrm{H} 1$ and PD-1 determines initiation and reversal of T-cell anergy. Blood. 110:180-185.

15. Day, C.L., et al. 2006. PD-1 expression on HIV-specific $\mathrm{T}$ cells is associated with T-cell exhaustion and disease progression. Nature. 443:350-354.

16. Barber, D.L., et al. 2006. Restoring function in exhausted CD8 T cells during chronic viral infection. Nature. 439:682-687.

17. Nurieva, R., et al. 2006. T-cell tolerance or function is determined by combinatorial costimulatory signals. EMBO J. 25:2623-2633.

18. Triebel, F., et al. 1990. LAG-3, a novel lymphocyte activation gene closely related to CD4. J. Exp. Med. 171:1393-1405.

19. Kisielow, M., Kisielow, J., Capoferri-Sollami, G., and
Karjalainen, K. 2005. Expression of lymphocyte activation gene 3 (LAG-3) on B cells is induced by T cells. Eur. J. Immunol. 35:2081-2088.

20. Huang, C.T., et al. 2004. Role of LAG-3 in regulatory T cells. Immunity. 21:503-513.

21. Gandhi, M.K., et al. 2006. Expression of LAG-3 by tumor-infiltrating lymphocytes is coincident with the suppression of latent membrane antigen-specific CD8+ T-cell function in Hodgkin lymphoma patients. Blood. 108:2280-2289.

22. Workman, C.J., Rice, D.S., Dugger, K.J., Kurschner, C., and Vignali, D.A. 2002. Phenotypic analysis of the murine CD4-related glycoprotein, CD223 (LAG-3). Eur. J. Immunol. 32:2255-2263.

23. Workman, C.J., and Vignali, D.A. 2005. Negative regulation of $\mathrm{T}$ cell homeostasis by lymphocyte activation gene-3 (CD223). J. Immunol. 174:688-695.

24. Workman, C.J., et al. 2004. Lymphocyte activation gene-3 (CD223) regulates the size of the expanding T cell population following antigen activation in vivo. J. Immunol. 172:5450-5455.

25. Macon-Lemaitre, L., and Triebel, F. 2005. The negative regulatory function of the lymphocyte-activation gene-3 co-receptor (CD223) on human T cells. Immunology. 115:170-178.

26. Adler, A.J., et al. 1998. CD4+ T cell tolerance to parenchymal self-antigens requires presentation by bone marrow-derived antigen-presenting cells. J. Exp. Med. 187:1555-1564.

27. Huang, C.T., et al. 2003. CD4+ T cells pass through an effector phase during the process of in vivo tolerance induction. J. Immunol. 170:3945-3953.

28. Workman, C.J., Dugger, K.J., and Vignali, D.A. 2002. Cutting edge: molecular analysis of the negative regulatory function of lymphocyte activation gene-3. J. Immunol. 169:5392-5395

29. Drake, C. G., et al. 2005. Androgen ablation mitigates tolerance to a prostate/prostate cancerrestricted antigen. Cancer Cell. 7:239-249.

30. Gingrich, J.R., Barrios, R.J., Foster, B.A., and Greenberg, N.M. 1999. Pathologic progression of autochthonous prostate cancer in the TRAMP model. Prostate Cancer Prostatic Dis. 2:70-75.

31. Li, N., et al. 2007. Metalloproteases regulate T-cell proliferation and effector function via LAG-3. EMBO J. 26:494-504.

32. Marzo, A.L., et al. 2000. Tumor-specific CD4+ $\mathrm{T}$ cells have a major "post-licensing" role in CTL mediated anti-tumor immunity. J. Immunol. 165:6047-6055

33. Adler, A.J., Huang, C.T., Yochum, G.S., Marsh, D.W., and Pardoll, D.M. 2000. In vivo CD4+ T cell tolerance induction versus priming is independent of the rate and number of cell divisions. J. Immunol. 164:649-655

34. Workman, C.J., and Vignali, D.A. 2003. The CD4related molecule, LAG-3 (CD223), regulates the expansion of activated T cells. Eur. J. Immunol. 33:970-979.

35. Morgan, D.J., et al. 1996. CD8(+) T cell-mediated spontaneous diabetes in neonatal mice. J. Immunol. 157:978-983.

36. Housseau, F., et al. 2002. Tumor-specific CD8+ T lymphocytes derived from the peripheral blood of prostate cancer patients by in vitro stimulation with autologous tumor cell lines. Int. J. Cancer. 98:57-62.

37. Fuessel, S., et al. 2006. Vaccination of hormonerefractory prostate cancer patients with peptide cocktail-loaded dendritic cells: results of a phase I clinical trial. Prostate. 66:811-821.

38. Pardoll, D. 2003. Does the immune system see tumors as foreign or self? Annu. Rev. Immunol. 21:807-839.

39. Zou, W. 2005. Immunosuppressive networks in the tumour environment and their therapeutic relevance. Nat. Rev. Cancer. 5:263-274

40. Chen, M.L., et al. 2005. Regulatory T cells suppress tumor-specific CD8 $\mathrm{T}$ cell cytotoxicity through TGF-beta signals in vivo. Proc. Natl. Acad. Sci. U. S. A. 102:419-424.

41. Mempel, T.R., et al. 2006. Regulatory T cells reversibly suppress cytotoxic $\mathrm{T}$ cell function independent of effector differentiation. Immunity. 25:129-141.

42. Thomas, D.A., and Massague, J. 2005. TGF-beta directly targets cytotoxic $\mathrm{T}$ cell functions during tumor evasion of immune surveillance. Cancer Cell. 8:369-380.

43. Rodig, N., et al. 2003. Endothelial expression of PDL1 and PD-L2 down-regulates CD8+ T cell activation and cytolysis. Eur. J. Immunol. 33:3117-3126.

44. Lees, J. R., et al. 2006. T-cell recognition of a prostate specific antigen is not sufficient to induce prostate tissue destruction. Prostate. 66:578-590.

45. Gavin, M., and Rudensky, A. 2003. Control of immune homeostasis by naturally arising regulatory CD4+ T cells. Curr. Opin. Immunol. 15:690-696.

46. Srivastava, P.K. 2006. Therapeutic cancer vaccines. Curr. Opin. Immunol. 18:201-205.

47. Small, E.J., et al. 2006. Placebo-controlled phase III trial of immunologic therapy with sipuleucel-T (APC8015) in patients with metastatic, asymptomatic hormone refractory prostate cancer. J. Clin. Oncol. 24:3089-3094.

48. Walker, E.B., et al. 2004. gp100(209-2M) peptide immunization of human lymphocyte antigen-A2+ stage I-III melanoma patients induces significant increase in antigen-specific effector and long-term memory CD8+ T cells. Clin. Cancer Res. 10:668-680.

49. Rosenberg, S.A., et al. 2003. Recombinant fowlpox viruses encoding the anchor-modified gp100 melanoma antigen can generate antitumor immune responses in patients with metastatic melanoma. Clin. Cancer Res. 9:2973-2980.

50. Demeure, C.E., Wolfers, J., Martin-Garcia, N., Gaulard, P., and Triebel, F. 2001. T Lymphocytes infiltrating various tumour types express the MHC class II ligand lymphocyte activation gene-3 (LAG-3): role of LAG-3/MHC class II interactions in cell-cell contacts. Eur. J. Cancer. 37:1709-1718.

51. Masopust, D., Vezys, V., Marzo, A.L., and Lefrancois, L. 2001. Preferential localization of effector memory cells in nonlymphoid tissue. Science. 291:2413-2417.

52. The Norman Greenberg Lab. Video Instruction Manual and Guide. http://thegreenberglab.fhcrc. org/research/research tramp_video.html. 